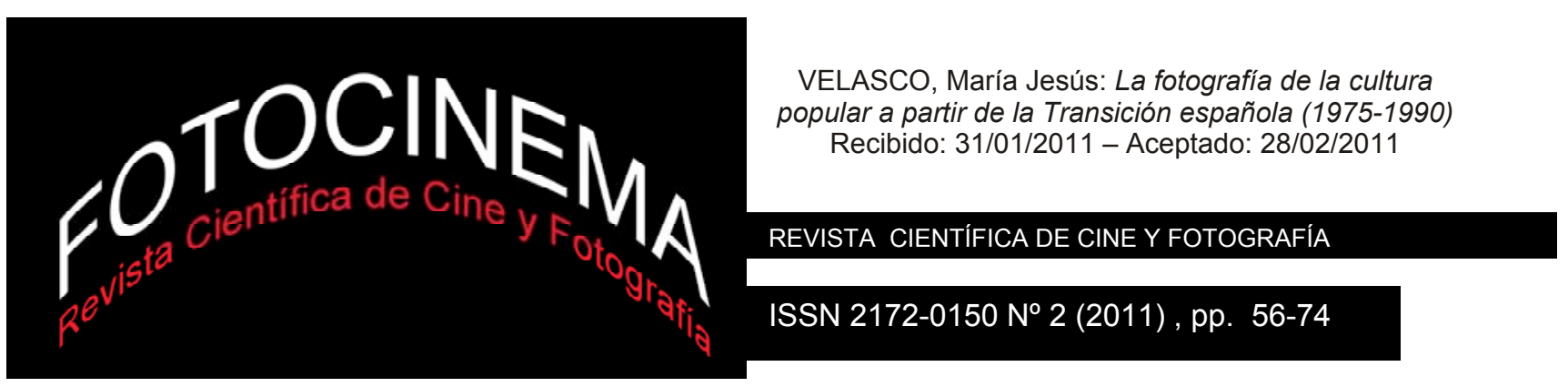

\title{
LA FOTOGRAFÍA DE LA CULTURA POPULAR A PARTIR DE LA TRANSICIÓN ESPAÑOLA
}

\section{POPULAR CULTURE PHOTOGRAPHY FROM THE SPANISH DEMOCRATIC TRANSITION}

\begin{abstract}
Resumen:
El profundo cambio que se produjo en nuestro país a partir de la transición democrática tuvo repercusiones en las manifestaciones de la cultura popular, lo que llevó implícito un consecuente cambio en las maneras de ver y, por lo tanto, de fotografiar los ritos y las tradiciones de nuestro país. Todo ello tuvo consecuencias en la diversidad de trabajos fotográficos y de publicaciones con imágenes que fueron viendo la luz durante las décadas siguientes. El texto hace un recorrido por ellas e inicia su andadura en los catálogos del Certamen Nacional de Fotografía sobre Artes y Tradiciones Populares, como ejemplo de la primera convocatoria específica institucional abierta al público, enmarcada en un ámbito democrático y participativo. Posteriormente, se detiene en lo fotógrafos y en los trabajos más significativos de la época, materializados en diversos libros fotográficos de autor. Enraizando con la proliferación del incipiente turismo cultural se analizan las fotografías de índole divulgativa de las primeras guías turísticas dedicadas específicamente a fiestas y a costumbres populares. Finalmente, se adentra en el ámbito académico a través del contenido fotográfico de varias revistas de antropología.
\end{abstract}

\section{Palabras clave:}

Fotografía; cultura popular; democracia; turismo cultural; antropología.

Key words:

Photography; popular culture; democracy; cultural tourism; anthropology.

\begin{abstract}
:
Democratic transition produced in Spain an important change that had a deep impact on the manifestations of popular culture and, consequently, altered the ways of looking and, therefore, taking photographs of rituals and traditions. This, therefore, had implications for a diversity of photographs and publications with images in later decades. In this essay we analyse them, taking as a starting point the catalogs of the National Photographic Competition on Art and Popular Traditions, which is the first institutional competition open to the public, within a context of democracy and participation. Later, we will have a look at the most important photographers and works of that moment, focusing on some author's photographic books. Closely related to the emergence of cultural tourism is the appearance of the informative photographs of the first travel guides specifically focused on festivals and popular traditions, which we analyze afterwards. Finally, in order to have an approach to the academic field we will analyse some photographs of several anthropology journals.
\end{abstract}




\section{Introducción}

Durante la Transición, España daba pasos definitivos hacia la modernización. La racionalización de la economía, el ingreso en la Comunidad Económica Europea y el desarrollo del turismo que había comenzado en los años 6o, cambiaban el semblante hacia un progreso que conllevaba mejoras políticas y económicas pero que también comportaba contrapartidas y pérdidas. Durante la década de los ochenta se dio un progresivo desarrollo de un turismo interior de tipo cultural, cuyos destinos empezaron a ser los museos, los sitios arqueológicos, los monumentos, los cascos antiguos de ciudades, las artes visuales, las artes aplicadas, las grandes exposiciones, la música, la danza, los festivales religiosos, las peregrinaciones, las rutas o itinerarios culturales, el folklore, etc. (MORÉRE MOLINERO, 1999: 702). En 1985 entró en vigor la ley del Patrimonio Histórico Español y al año siguiente, fue aprobado el Real Decreto 111/1986 que desarrolla parcialmente la ley. En el ámbito internacional en 1989, la UNESCO aprobó la Recomendación sobre la Protección de la Cultura Tradicional y Popular.

También, durante este periodo, nació lo que conocemos como turismo rural, que tiene claros puntos coincidentes con el turismo cultural, aunque conserva muchas especificidades. El turismo rural se inicia a principios de los años ochenta, aunque se desarrolla principalmente durante la década de los noventa. La actividad turística que se comenzó a desarrollar en el medio rural tenía como motivación principal la búsqueda de atractivos turísticos asociados al descanso, al paisaje, a la cultura tradicional y a la huída de la masificación. Las actividades turísticas en el ámbito rural fueron incentivadas por la Unión Europea a través de la política agraria, la política regional y las diversas iniciativas comunitarias.

En lo que se refiere a las fiestas y a los rituales folklóricos, tras la transición democrática, las leyes coercitivas sobre las celebraciones populares 
desaparecieron ${ }^{1}$. Los carnavales volvieron a formar parte del calendario e incluso se impulsó oficialmente su celebración (GONZÁLEZ, 2002: 88). Ello contribuyó definitivamente a revitalizar los ritos del ciclo de invierno, fundamentalmente el carnaval. Pero el verdadero impulsor del universo simbólico y paródico de las manifestaciones festivas laicas de la cultura popular fue la emergencia de un fuerte deseo colectivo de experimentación en el proceso de búsqueda de nuevas formas de presencia pública y emoción colectiva compartida, que empezaba a manifestarse en este momento, sobre todo entre los sectores más jóvenes (MUÑOZ CARRIÓN, 2008). Esta pasión de los jóvenes por las fiestas, según Enrique Gil Calvo (1991: 120), es debida a que en ellas encuentran:

“...algo que su realidad social les negaba, quizá: el reconocimiento y exaltación de su libertad personal [junto con otras motivaciones:] desde la coacción tácita e informal que ejerce el medio social hasta la espuria satisfacción de los intereses arribistas, pasando por la pura y simple búsqueda de la gratificación y el placer corporal (...) Si la fiesta embriaga es porque emborracha de libertad. Entregarse a la fiesta es emanciparse, liberarse, desencadenarse y desprenderse de cualquier atadura anterior o vinculación previa (...) Huyes del oscurantismo y huyes del poder que te sujetan, asociados al vigente orden social de tu familia, tu trabajo y tu comunidad (...) Gracias a la fiesta, puedes eludir el poder del poder, proponiendo como culminación la imposible pero perfecta utopía de la fiesta permanente e indefinida".

Por otra parte, las celebraciones religiosas, que contaban con la ferviente adhesión de algunos sectores sociales más mayores, despertaban también el rechazo de otros grupos que veían en ellas el reflejo de toda una época de radical nacional-catolicismo (MUÑOZ CARRIÓN, 2008).

\footnotetext{
${ }^{1}$ Desde la Dictadura de Franco se desarrolló una política coercitiva que afectó de lleno a las celebraciones profanas del ciclo de invierno, fundamentalmente al Carnaval. Si durante la República (1931-1936), las medidas prohibitivas anteriores respecto a la celebración del Carnaval habían sido abolidas, con el estallido de la guerra civil todas las manifestaciones festivas fueron suprimidas oficialmente. Sin embargo, a pesar de que las autoridades impusieran estrictos límites a la libertad festiva, no consiguieron eliminarla. La fantasía, el erotismo y el afán colectivo por la igualdad resistieron camuflados en diversos rituales (BRISSET, 2009).
} 


\section{La popularización de la fotografía y el nacimiento del Certamen} Nacional de Fotografía sobre Artesanía, Tradiciones y Costumbres de los Pueblos de España

En lo que se refiere a las imágenes, la popularización de la fotografía se hacía cada vez más evidente en una sociedad en la que la tecnología fotográfica se había hecho accesible a una mayoría importante de la población. Además de expansión de cámaras compactas de $35 \mathrm{~mm}$., el uso de las cámaras fotográficas DSLR de paso universal, comúnmente llamadas Réflex, se había hecho extensivo a un numeroso público aficionado, que empezaba utilizar la fotografía con profusión. Muchos de estos aficionados empezaron a ampliar sus conocimientos visuales y técnicos y a desarrollar destrezas entrando a formar parte de un numeroso grupo de lo que desde el mercado fotográfico se empezó a considerar como "semi-profesionales" de la fotografía. Algunos se quedaron ahí, pero otros se fueron profesionalizando o emprendieron trabajos personales desde el ámbito artístico. En este sentido, conviene no olvidar que hasta la década de los ochenta la fotografía no empezó a tener en España el estatus de Arte al que hoy estamos habituados.

Por otro lado, la democratización y la nueva organización descentralizada del Estado abrían nuevos cauces de participación de la población en la vida cultural. Desde las administraciones locales, desde las recién creadas comunidades autónomas y desde el propio Ministerio de Cultura empezaron a surgir iniciativas de carácter sociocultural cuya pretensión principal era el fomento de la participación de los ciudadanos en los diversos campos culturales. Un ejemplo de este progresivo interés por la incentivación de la cultura mediante cauces participativos surgió en 1983 con la convocatoria del Certamen Nacional de Fotografía sobre Artesanía, Tradiciones y Costumbres de los Pueblos de España². El certamen nacía sin parangón en una sociedad que, tras haber abandonado el interés por lo tradicional y lo

2 Certamen de Fotografía sobre Artesanía, Tradiciones y Costumbres de los Pueblos de España, creado mediante orden de 29 de julio de 1983. 
popular, volvía, tras los pasos de un nuevo turismo alternativo de índole cultural y rural, a poner su mirada en los pueblos y aldeas abandonados por sus familias dos décadas atrás.

El Certamen supuso un punto de inflexión muy importante, sobre todo en lo que respecta al tipo de discurso que planteó. Por primera vez en el territorio nacional se lanzó una convocatoria fotográfica en torno al referente de la cultura popular abierta al público en general. Nuevas y múltiples voces estaban convocadas a través de la fotografía a contribuir en la construcción del repertorio de las imágenes de la cultura popular desde una óptica democrática que iba más allá de los discursos monológicos del ámbito académico y empezaba a ser dialógica. Los antropólogos ya no eran los únicos autorizados a aportar su manera de mirar la realidad de la vida popular, ya que desde la esfera institucional el Ministerio de Cultura, se validaban por primera vez las representaciones fotográficas de ciudadanos interesados en aportar su visión particular del mundo tradicional a través de sus fotos. Fotos, que se daban a conocer mediante publicaciones en papel -catálogos fotográficos- y exposiciones. Así, las sucesivas convocatorias del Certamen han ido dando lugar a la producción y recolección de un material visual singular muy significativo por el gran caudal de "maneras de mirar" lo que hoy conocemos como patrimonio cultural inmaterial, dada la pluralidad de voces que lo han ido confeccionando.

Una de las mayores cualidades que podemos encontrar en este material fotográfico es su organización en pequeñas series. Las diferentes convocatorias anuales contemplaban la presentación de varias fotografías en torno a un tema -normalmente de tres a cinco- y no primaban solamente la imagen única. Esto supuso un primer paso hacia delante, ya que era un buen indicativo de la necesidad de abordar trabajos visuales con cierta profundidad basados en la serie fotográfica y no tanto en imágenes fotográficas únicas "anecdóticas o impactantes", en la mayor parte de los casos. La inclusión de los datos técnicos en los reportajes premiados, seleccionados o que recibieron alguna mención honorífica, publicados en los catálogos anuales del Certamen, supone otra de sus particularidades. Contar 
con los detalles técnicos de las fotografías publicadas -tipos de cámaras, película, a veces focales, aperturas de diafragma y velocidades- ayuda en gran medida a realizar análisis mucho más exhaustivos y precisos. Las especificidades técnicas constituyen una valiosa batería de elementos a la hora de estimar con mayor precisión los trabajos fotográficos.
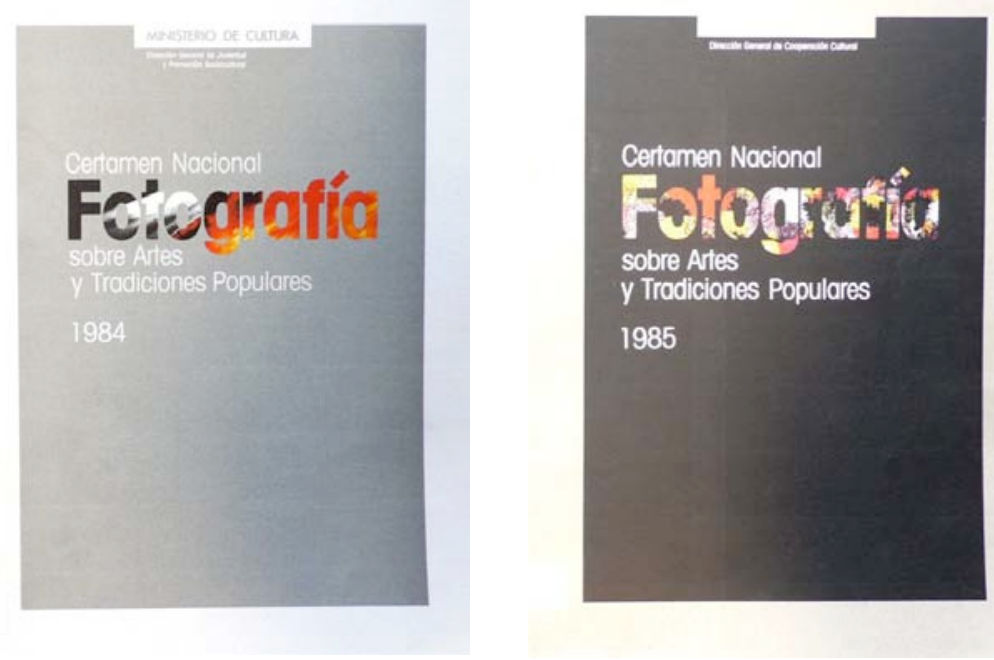

Portadas de los catálogos del Certamen Nacional de Fotografía sobre Artes y Tradiciones populares de 1984 y 1985.

\section{Los libros fotográficos de autor}

Es indudable que el Certamen supuso un hito en la trayectoria de la imagen fotográfica de la cultura popular en España. Durante la primera fase de su recorrido hizo públicos trabajos fotográficos de autores que pocos años más tarde iban a tener una proyección muy importante. Entre ellos cabe destacar a César Justel y a Cristina García Rodero (1949). Los trabajos de César Justel fueron publicados en diversos catálogos del Certamen tras ser premiados y seleccionados. Varios años después, en la década de los noventa, el autor realizó una gran mayoría de las imágenes de la Enciclopedia de las fiestas Españolas de Diario 16 (1993), posteriormente publicó un libro fotográfico de autor titulado Fiestas Españolas (1997). Las series de Cristina García Rodero también fueron premiadas, seleccionadas y obtuvieron menciones honoríficas en varias convocatorias seguidas. Algunas de las fotografías de 
estos trabajos presentados al Certamen formaron parte poco después de publicaciones tan emblemáticas como España Oculta (1989) o España fiestas y ritos (1993).

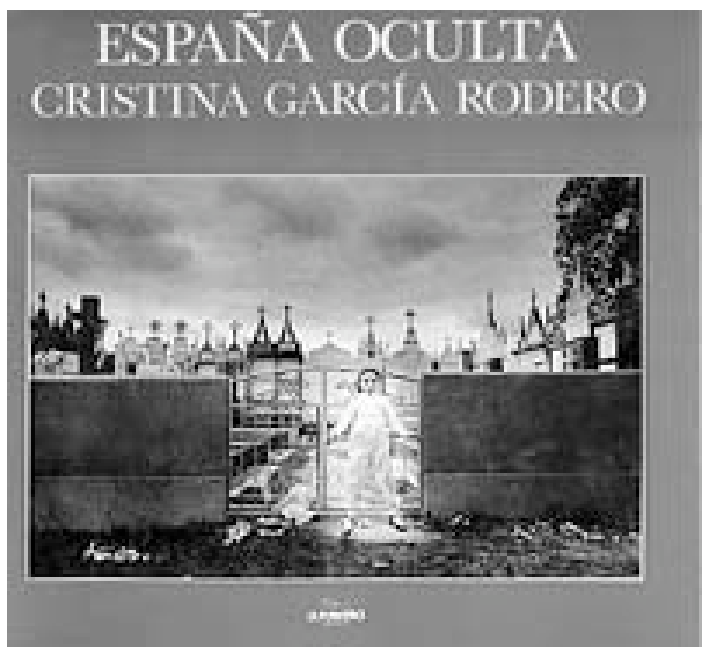

Portada de España Oculta (1989).

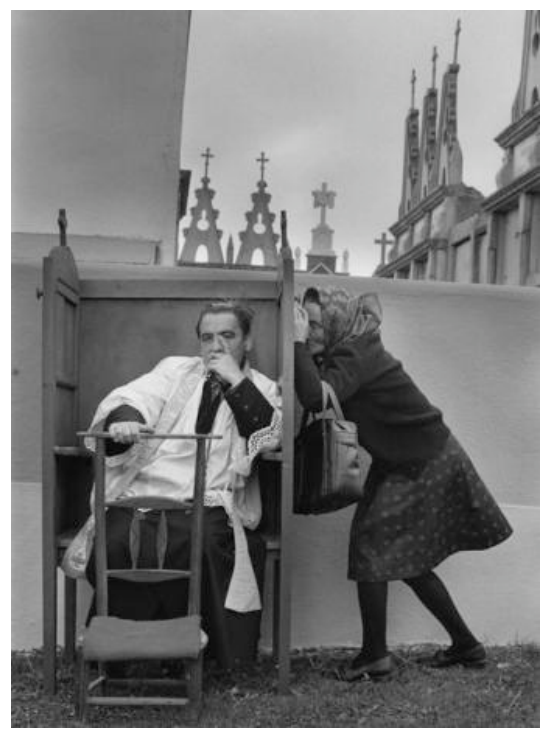

Fotografía $\mathrm{n}^{0}$ 114, La confesión, 1980.

España Oculta fue publicado en 1989, aunque muchas de sus fotografías fueron realizadas por Cristina García Rodero durante los años 70 y $80 . \mathrm{El}$ prólogo de Julio Caro Baroja alude a la España tradicional y popular no dominada por las formas de un supuesto progreso que se iban imponiendo:

"Aquí estamos ante una serie de imágenes que reflejan la fe religiosa, las diversiones y la vida cotidiana de infinidad de personas con sus usos y sus costumbres, su economía y cultura no dominadas por formas que se van imponiendo de modo evidente y que muchos consideran sinónimas de progreso y que otros podemos pensar que son más modernas y distintas, pero sin añadir en esto nota o beatífica alguna." (Caro Baroja, 1989).

El antropólogo estadounidense Stanley Brandes (2005: 238) declara que España Oculta tiene un gran interés desde el punto de vista de la disciplina antropológica. Se trata, según él, de un interés triple que abarca lo histórico, lo etnográfico y lo metodológico. Desde el punto de vista histórico, el libro representa la máxima expresión artístico-documental de la sociedad post- 
franquista. Las fotografías de García Rodero muestran una España en la que el control estatal se había aflojado. Se puede apreciar en ellas libertad de comportamiento, junto con cierto desorden en la manera de realizar los actos religiosos. Se aprecia así que los propios vecinos, y no el clero o el Estado, son los que dirigen la fiesta y deciden cómo y cuándo respetar o romper con las normas políticas y eclesiásticas. El libro tiene además una dimensión etnográfica, ya que desvela detalles de mucho interés antropológico.

Desde el punto de vista metodológico, en España oculta las fotos no están organizadas por zonas, ni por pueblos, ni por temporada del año, ni siquiera por año. A diferencia de Ortiz Echagüe, que clasificaba e identificaba sus fotografías de acuerdo con entidades geográficas o fiestas específicas, para Cristina García Rodero todo esto tiene una importancia secundaria. Ella indica el pueblo y la fecha en la que se tomó la fotografía, también suele nombrar la fiesta o describir la actividad de la fotografías a través del título. Pero toda esta información aparece al final del libro y no, como es frecuente, al lado de cada fotografía. Para el público no informado estos títulos que hacen referencia a personajes como "la Maya” o "el Cascamorras" no tienen ningún significado. En este sentido opina Jesús María de Miguel (1999, pág. 37), quien, aunque considera estético y ambicioso el proyecto fotográfico de España Oculta de Cristina García Rodero, alude a la falta de un análisis serio en sus planteamientos.

Hubo otros fotógrafos que se dedicaron a realizar reportaje de autor de carácter antropológico. Fernando Herráez, Koldo Chamorro, Ramón Zabalza y Cristóbal Hara fueron bautizados, junto a Cristina García Rodero, como "los cinco jinetes del apocalipsis" por Alejandro Castellote 3 por su actitud incansablemente viajera por los pueblos españoles.

Para muchos de estos fotógrafos, el referente de la cultura popular y las tradiciones era un motivo singular desde el que desarrollar su expresividad y sus trabajos de autor. Teniendo en cuenta los objetivos de estos fotógrafos, es

3 Alejandro Castellote es comisario de exposiciones de fotografía y profesor. Ha dado multitud de conferencias sobre fotografía y ha sido Director Artístico de PHotoEspaña.

63 
interesante hacer lecturas actualizadas de sus trabajos que pongan sobre la mesa y abunden en sus maneras de mirar y en lo que se esconde detrás de sus propuestas. Más que buscar solo el rigor documental en las fotografías, habría que sondear en ellas para encontrar enfoques inéditos y visiones valiosas e intensas de nuestra cultura popular. Mirarlas como lo que son, invitaciones a la especulación y a la reflexión, y no tanto como certezas, enriquecerá el abanico de propuestas y surtirá de material estilístico a las futuras iniciativas de registro y documentación gráfica de la cultura popular.

Cristóbal Hara (1946) publicó su trabajo Lances de aldea en 1992. Este trabajo era el fruto de su acercamiento al toreo rural en España a través de sus amigos los maletillas. Desde hacía años, Cristóbal Hara había sido testigo de la vida cotidiana de los pueblos españoles, fotografiándolos como si formara parte de ellos, fusionando el documento con las emociones y obteniendo como resultado un trabajo de índole muy personal (CONESA, 2000).

En 1998 Cristóbal Hara también publicó otro trabajo fotográfico en forma de libro con el título de Vanitas4, que fue producto de muchos viajes por España con la muerte como centro de atención. Ignacio González (1998) en el prólogo del libro describe el trabajo de Hara así:

"Al igual que en los cuadros que denominamos VANITAS, la muerte tiene por costumbre aparecer en muchas de las manifestaciones más brillantes de la cultura española. De Teresa de Jesús a Federico García Lorca; de Valdés Leal a Dalí, pasando por Goya y por Solana, la muerte es una presencia familiar y cotidiana. En este libro, impregnado de un humor sutil, y con la muerte como compañera de viaje, Cristobal Hara nos trae imágenes que plasman -mejor que las guías y las rutas monumentales- esa especial personalidad que la España contemporánea y europea aún acierta a conservar".

En Cristóbal Hara se aúnan la fotografía documental y la creación subjetiva. Elige los escenarios tradicionales de la imaginería popular, las costumbres, lo religioso, y los aborda de una manera inequívocamente moderna. Según Rosa Olivares (2005), Hara "es moderno a pesar suyo, innovador a pesar de los temas tratados".

4 El libro Vanitas (1999) recibió el Premio al Mejor Libro de Fotografía del año en PHotoEspaña 1999. 

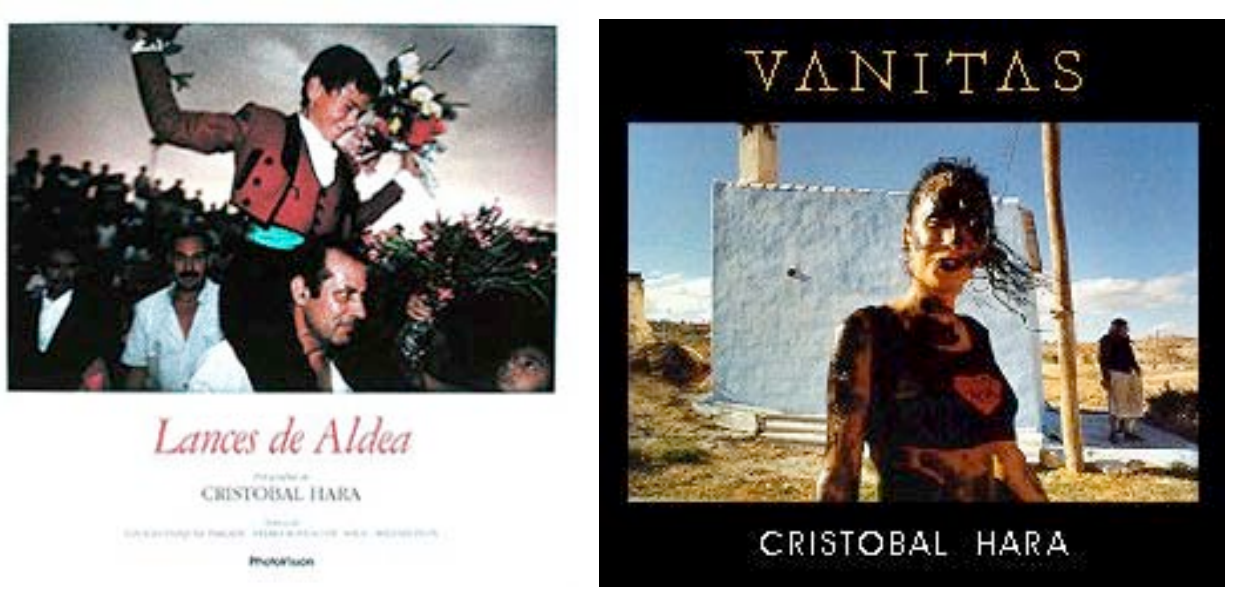

Portada de los libros de Cristóbal Hara, Lances de Aldea, 1992 y Vánitas, 1998.

Hara ironiza a partir de crear enfrentamiento casuales entre lo dramático y lo cómico, la burla de lo sagrado con lo profano. Retrata una España popular en la que se cruzan generaciones, tradición y renovación. Retrata de manera aparentemente casual el enfrentamiento entre contrarios: entre la infancia y la vejez, la muerte y la vida; sin embargo, sus imágenes no tienen nada de casual, son trabajadas, buscadas sistemáticamente. Hara elige lo que aparentemente no tiene importancia para sus encuadres y mira hacia donde parece que no pasa nada. Ese instante irrelevante es para él principal, con ello demuestra que todos los instantes son decisivos. Deja de lado lo más grueso de la historia en sus encuadres y se centra en los detalles, en lo que sucede en los márgenes de la historia central.

La obra de Koldo Chamorro (1949-2009) constituye también una aportación decisiva al nuevo lenguaje en la fotografía documental española. Entre otros, destacan sus trabajos España Mágica, El Santo Cristo Ibérico o Los Sanfermines. El fotógrafo acometió en sus proyectos tareas de catalogación de las tradiciones paganas y religiosas de España. Su trabajo El Santo Cristo Ibérico quizá sea el ensayo fotográfico en el que sintetiza mejor ese interés casi obsesivo por los símbolos en la vida cotidiana. La aparición de la cruz católica en todo tipo de escenarios es el hilo argumental que ilustra la persistencia de la tradición religiosa de nuestro país, pero también es una estrategia para evidenciar, desde situaciones cercanas al surrealismo, las 
contradicciones de una sociedad que se pretende moderna y laica, pero que convive con los rituales atávicos del pasado (Castellote, 1998).

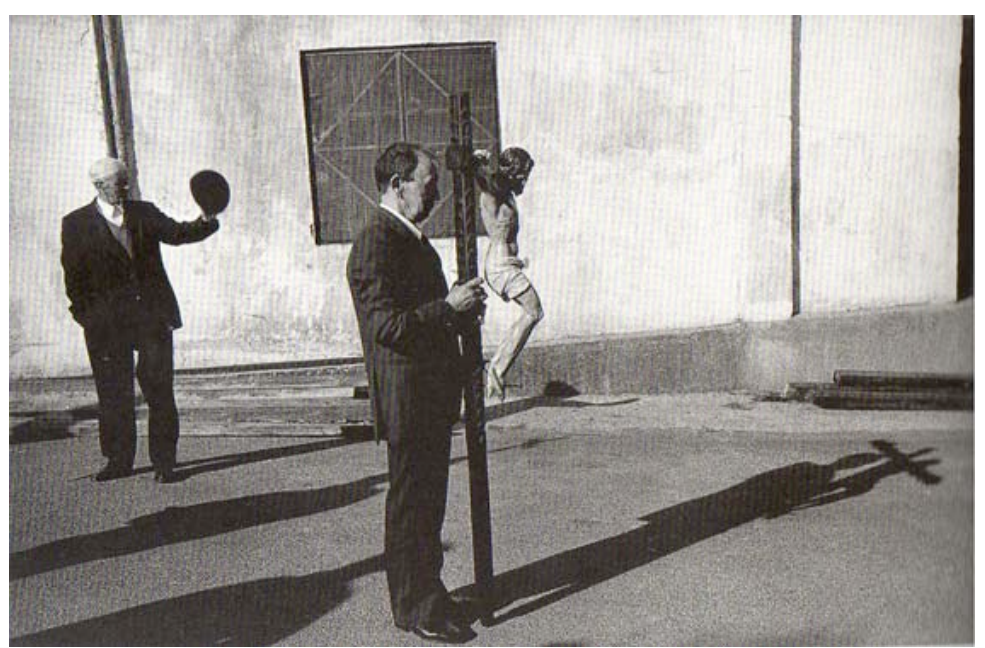

Koldo Chamorro, fotografías de Santo Cristo ibérico, Salamanca, 1995.

Fernando Herráez (1948), otro de los fotógrafos de la misma generación, casi siempre eligió escenarios rurales para sus trabajos fotográficos. Ritos

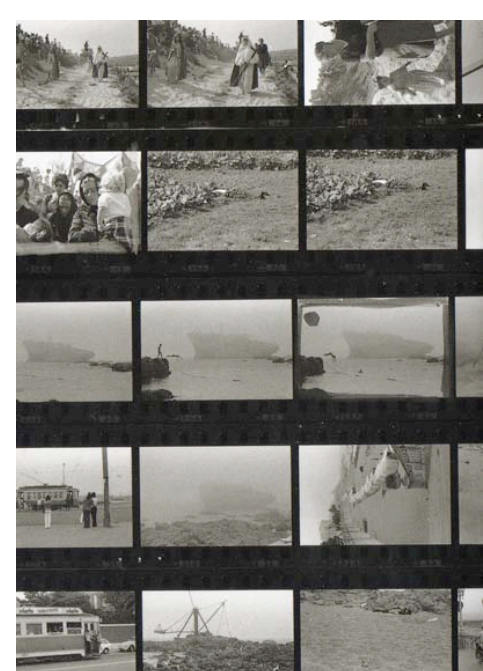
ibéricos, Sangre de toro, Líneas de playa, Terra incógnita y ciudades perdidas, son algunos de los títulos de sus trabajos. Su arte, según Luis Carandell (2001), con quien trabajó en la Revista Viajar5, consiste en relacionar íntimamente al personaje de la fotografía con el paisaje en el que se encuentra.

Contactos fotográficos, Fernando Herráez.

Ramón Zabalza realizó en estos años una muy interesante empresa fotográfica documental. Se trataba de un trabajo de gran envergadura acometido desde la profundidad que dio lugar a la publicación del libro Imágenes gitanas (1996). Algunas palabras de la introducción fueron escritas por el propio autor y develan las claves de cómo emprendió el autor

5 La revista Viajar fue fundada por Luis Carandell y Javier Gómez Navarro en 1978. 
este proyecto de carácter claramente antropológico, tanto por su contenido, como por la metodología con la que lo llevó a cabo.

"Los viajes a la España profunda y el descubrimiento de la antropología suscitaron en mí el deseo de asomarme a culturas diferentes, que me proporcionasen una mejor comprensión de la mía. Los rasgos diferenciales de los gitanos españoles me impulsaron, a comienzos de los años setenta, a elegirlos para este empeño. (...) La fotografía fue una de las herramientas que, junto con el cuaderno de notas, manejé desde el principio para llevar adelante mi proyecto. (...) cuando en 1973 descubrí "la fotografía", me asombré de la facilidad con que abandoné un año de trabajo de campo para correr en pos de la nueva perspectiva que ella me brindaba. Estas fotografías son, en gran medida, consecuencia del profundo cambio en la forma de mirar que entonces comenzaba”.

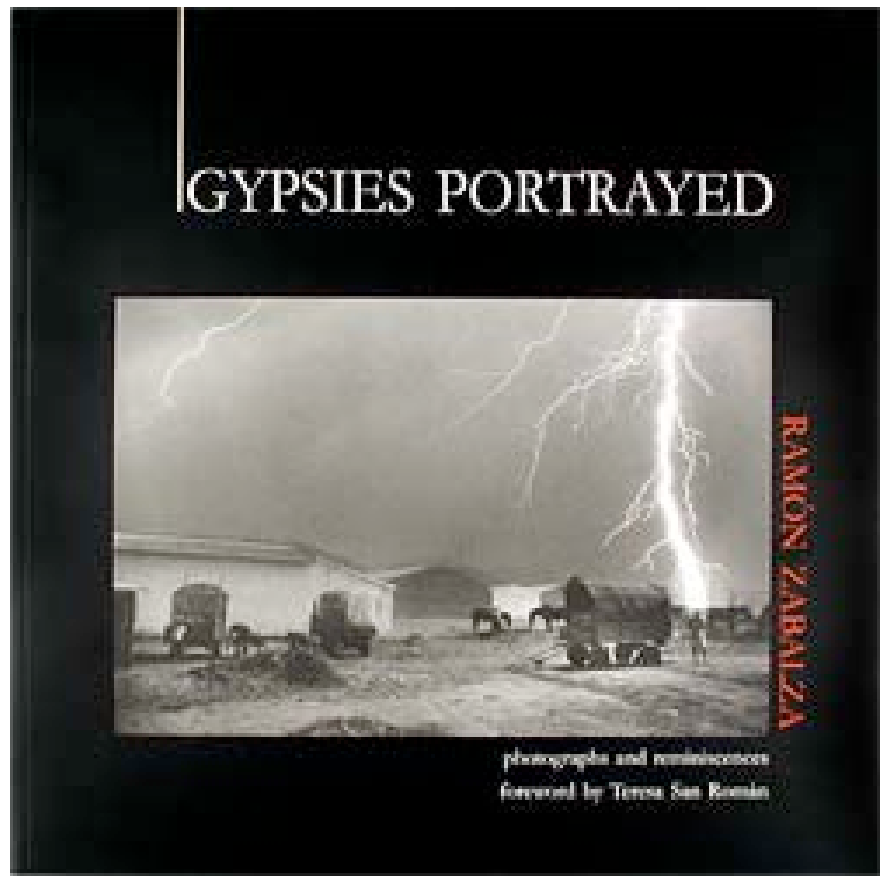

Portada de Imágenes gitanas de Ramón Zabalza, (1996). Premio Internacional del Libro Fotográfico $8^{\text {a }}$ Primavera Fotográfica de Barcelona en ese mismo año.

\section{4.- La imagen fotográfica divulgativa de las guías turísticas de fiestas populares}

Como consecuencia del aumento del turismo empezaron a surgir otro tipo de publicaciones en formas de guías de tipo divulgativo en torno a las fiestas populares españolas que trataban de acercar a los turistos a las celebraciones, informándoles de la gran oferta festiva que poseía el país e incitándoles a 67 
visitarlo. La primera de estas publicaciones fue la Guía de fiestas populares de María Ángeles Sánchez (1982). Esta guía, manejable y de pequeño formato, incorporaba una pequeña ficha informativa de cada celebración con datos detallados sobre el lugar preciso y la hora de comienzo de los eventos. También incluía numerosas imágenes fotográficas de pequeño formato que recogían lo que era considerado, desde la mirada foránea, como la escena o el elemento "más significativo de cada fiesta". Estas fotos mostraban, desde la excesiva simplificación, una imagen tipificada y seriada de la fiesta, al modo en que lo hacen las postales turísticas.
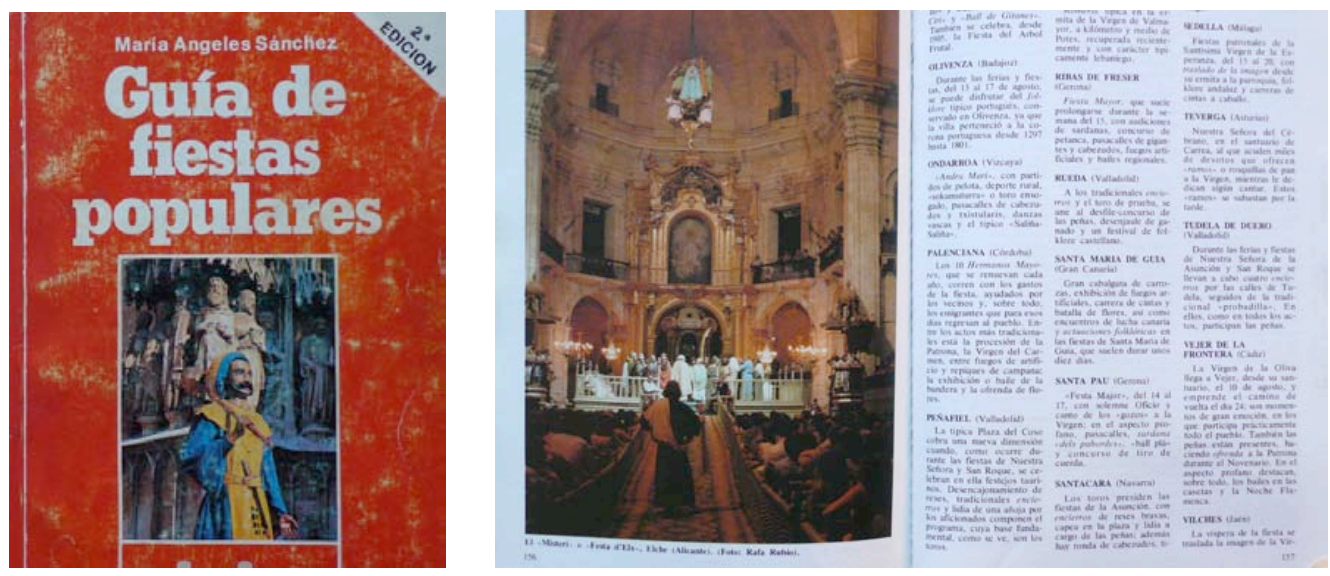

Portada de la Guía de fiestas populares, 1982. Páginas interiores con fotografía de la representación del Misterio de Elche.

Este tipo de pequeñas imágenes simplificadas empezaban a calar en el imaginario del viajero generando expectativas que poco tenían que ver con la complejidad de las celebraciones. El viajero quería comprobar que la "postal" que vio coincidía con la realidad que visitaba, cuando en realidad esa "imagen postal", esa imagen estereotipada, correspondía a una única fracción de segundo de lo que suponía la complejidad de la fiesta.

En 1987 Luis Agromayor publicó un libro de gran formato titulado España en Fiestas abordando el tema de una manera más amplia y contextualizada. Lo interesante y particular de esta publicación es cómo va de lo general a lo particular situando al lector en el contexto a través del mapa y de la

\footnotetext{
${ }^{6}$ María Ángeles Sánchez es periodista, escritora, fotógrafa y editora. Su trayectoria profesional ha estado dedicada a recorrer y a dar cuenta a través de numerosos medios españoles y extranjeros de las fiestas y celebraciones de nuestro país.
}

68 
panorámica fotográfica, para posteriormente llevarlo hacia lo particular de una forma sistemática y metódica. Los textos están equiparados a las imágenes y transcurren de forma paralela a ellas complementándose mutuamente. Los pies de foto tienen un papel preponderante, son extensos orientando el sentido, siempre polisémico, de las fotografías hacia descripciones detalladas a través de una clara función de anclaje ${ }^{7}$ de significado.

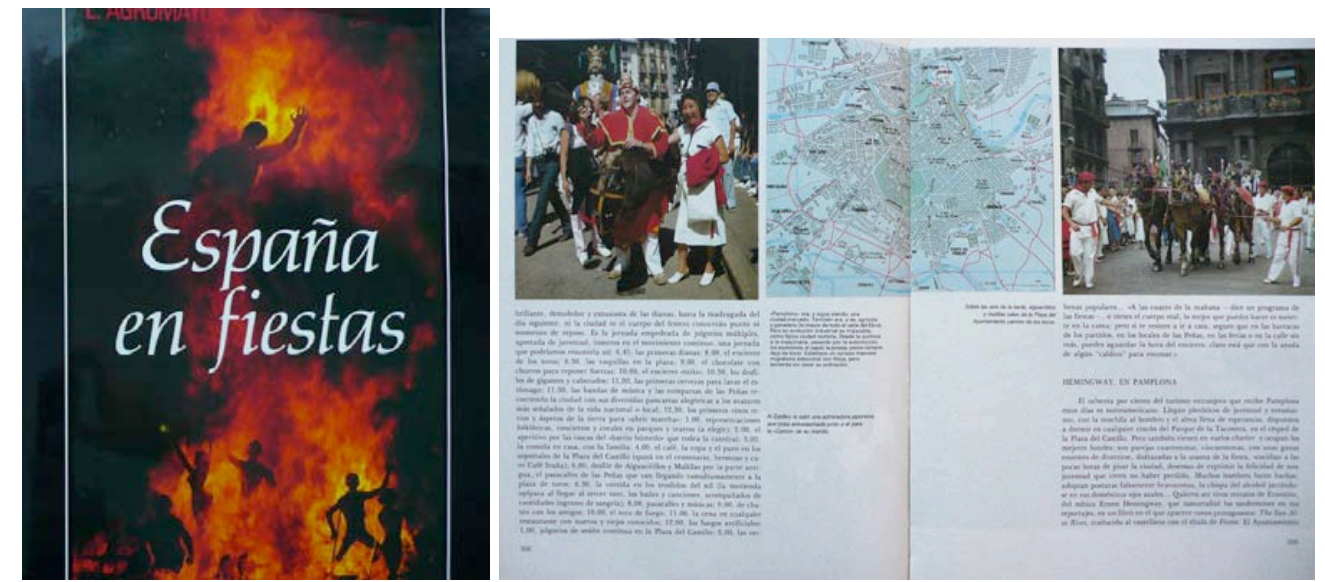

Portada y páginas interiores de España en fiestas de Luis Agromayor, 1987. Además de incluir fotografías paralelas a un texto, introduce imágenes panorámicas y mapas de situación.

\section{El contenido fotográfico de las publicaciones de antropología}

En 1975 la Universidad Autónoma de Madrid lanzó la Revista Narria. Estudios de artes y costumbres populares. La publicación rompió rotundamente con el formato de las revistas académicas del momento. La flexibilidad de la portada, un tamaño mayor, menor número de páginas y la impresión de imágenes en blanco y negro hicieron que la revista adquiriera un talante más versátil y manejable que sus coetáneas. La revista, dirigida desde el Museo de Arte Populares del Departamento de Prehistoria y Arqueología de la Facultad de Filosofía y Letras de la UAM, centró sus ediciones, que se prolongaron hasta el año 2006, en números monográficos

7 En el sentido que Roland Barthes da al término en La retórica de la imagen.

69 
dedicados a presentar estudios sobre diversas comarcas y provincias españolas.

Las fotografías que incluía Narria complementaban los textos escritos y aportaban contenido en muchos casos, en otros sin embargo cumplían una mera función ilustrativa. Se publicaban también, al lado de las fotografías, algunos dibujos explicativos de carácter didáctico. Lo cierto es que, en general, fotografías y dibujos contribuían conjuntamente a enriquecer el contenido de las exposiciones escritas, a pesar de que la calidad de las imágenes era muchas veces algo escasa y, a veces, las tomas pecaban de simplicidad, puesto que basaban sus planteamientos visuales sólo en el contenido de las imágenes y no prestaban demasiada atención a los elementos estilísticos.
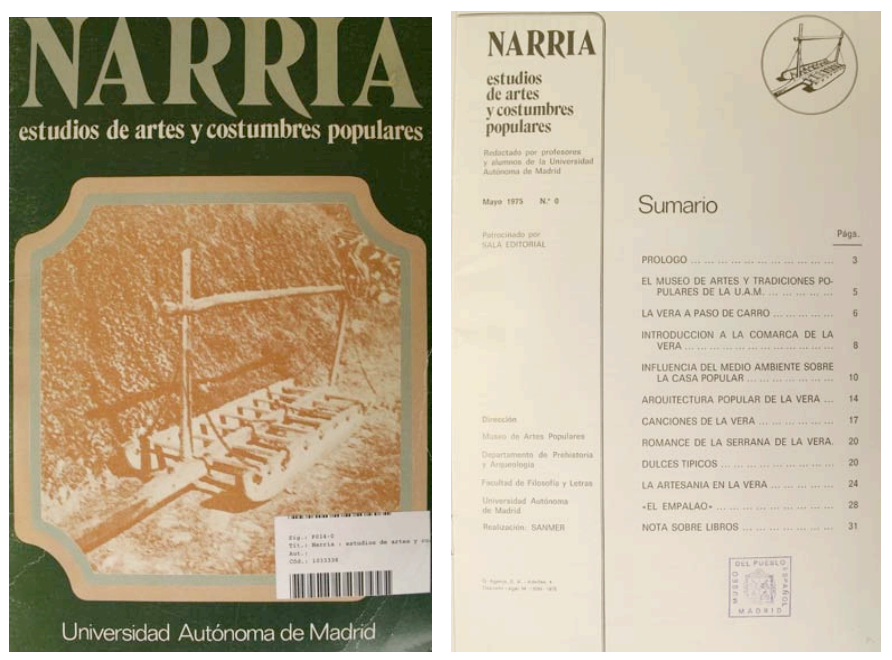

Portada y sumario del $\mathrm{n}^{\circ} \mathrm{O}$ de la revista Narria publicado en 1975, dedicado monográficamente a la Comarca de la Vera de Cáceres.

De todas formas es difícil hacer una valoración global del contenido visual de la revista Narria. Cada número incluía un repertorio de imágenes, en torno al contenido específico de cada provincia estudiada, que no guardaba demasiada homogeneidad con los demás. La línea editorial respetó estas diferencias haciendo una puesta en página adaptada a cada caso, de la que podemos destacar el sincronismo entre los textos y las imágenes, presente en toda la publicación. 


\section{NARRIA}
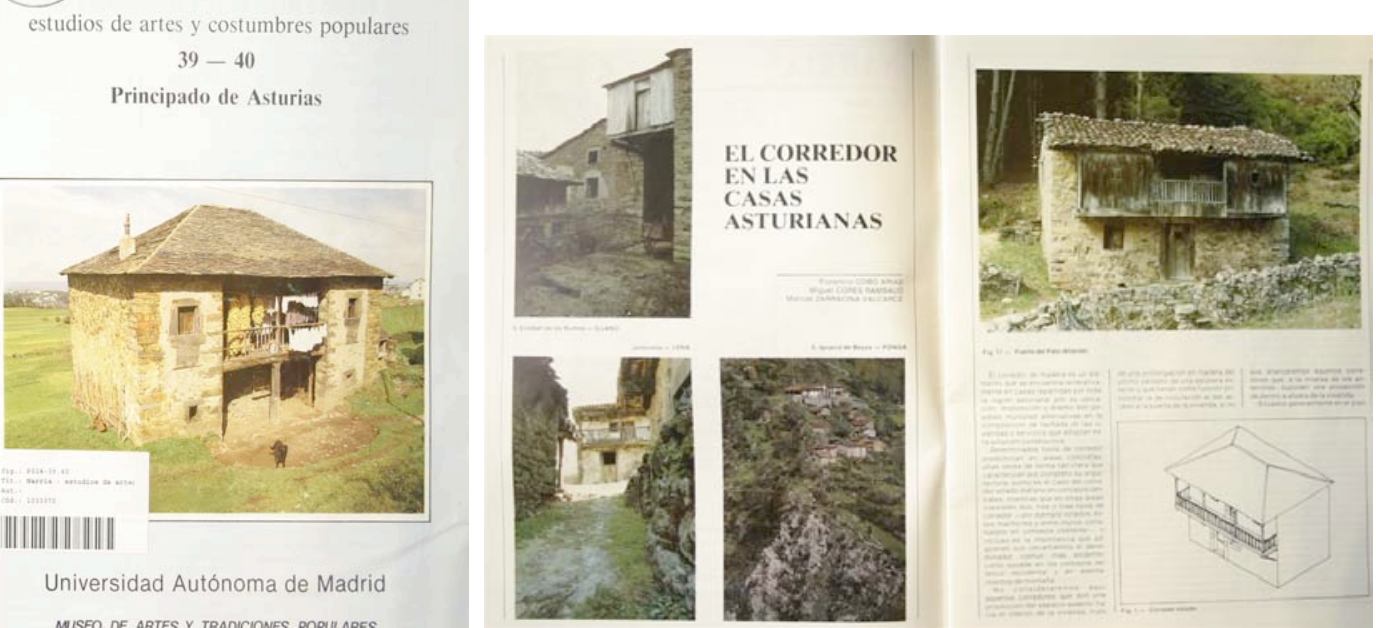

A partir de 1984 la revista Narria. Estudios de artes y costumbres populares comienza publicar fotografías en color

En 1980 el Ministerio de Cultura comenzó a publicar la Revista Etnografía Española. Su temática abundaba en el estudio de las diversas manifestaciones de la cultura popular, sobre todo de los procesos de producción de las artesanías, los oficios tradicionales y los modos de producción agrícola y ganadera.

La aportación más importante de la revista Etnografía Española desde el punto de vista visual fue la incorporación de secuencias fotográficas que registraban los procesos de trabajo tradicionales. Los pies de foto contribuían a completar la información de tal manera que el espectador pudiera seguir el desarrollo del trabajo paso a paso. La puesta en página de varias fotografías ordenadas secuencialmente ofrecía la posibilidad de "leer" de forma "sincrónica" un proceso de carácter "diacrónico". El primer golpe de vista permitía captar en pocos instantes las generalidades del procedimiento. Una lectura más exhaustiva daba la posibilidad de entrar en los pormenores técnicos de cada elaboración haciendo un seguimiento detallado de carácter cronológico. La estrecha e inseparable relación entre la destreza y el objeto, entre lo inmaterial y lo material de la tradición, quedaba patente en esta estrategia de representación fotográfica realizada con unos criterios metodológicos muy sólidos y muy coherentes durante toda la publicación. 
Además de incluir fotosecuencias, la revista incorporaba fotografías que catalogaban objetos y construcciones de la cultura popular.
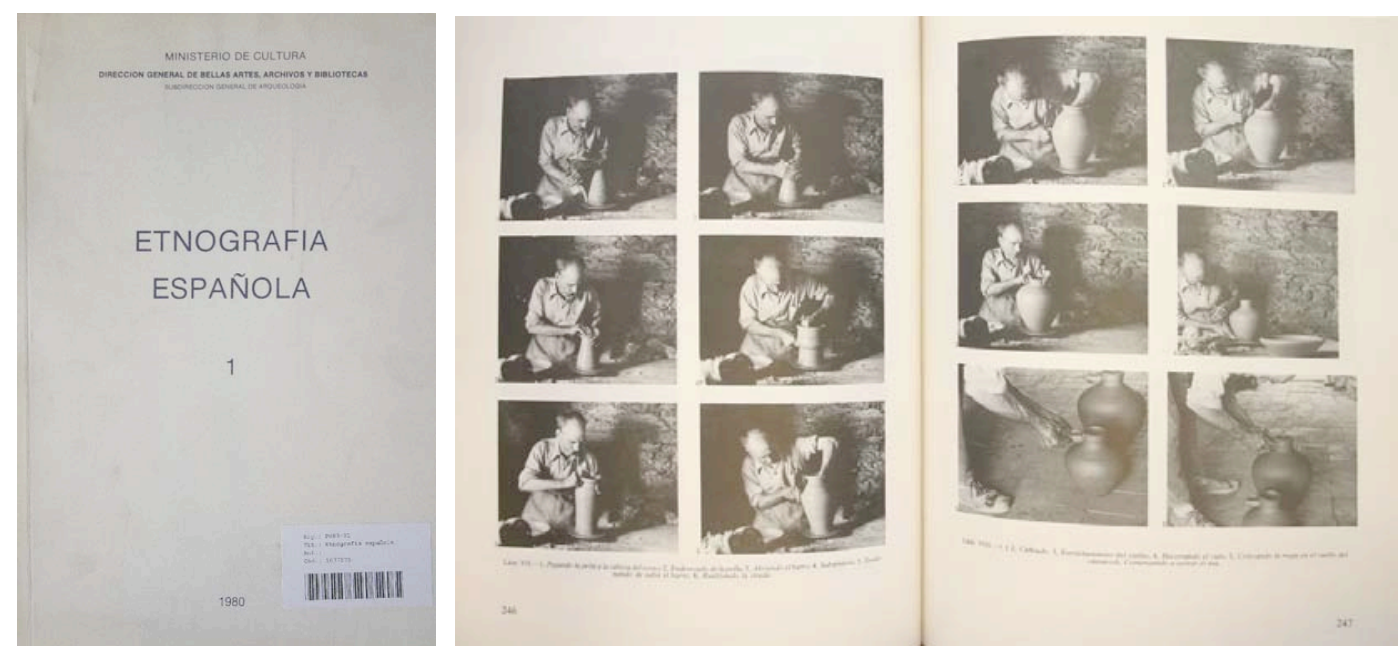

Portada y páginas interiores del $\mathrm{n}^{0} 1$ de Etnografía Española, 1980 . Secuencia de fotografías del proceso tradicional de realización

\section{Conclusiones}

El marco político y social, junto al desarrollo técnico de la fotografía, determinan profundamente las manera de mirar y de representar la cultura popular. La instauración y consolidación de la democracia se corresponde con el paulatino y cada vez mayor acceso a la práctica fotográfica, mediante la producción de imágenes con cámaras de $35 \mathrm{~mm}$., cada vez más accesibles, y abriendo paso a espacios de participación en el ámbito de la fotografía de ritos y costumbres, como el Certamen de fotografía sobre culturas populares convocado desde el Ministerio de Cultura. Éste espacio supuso el punto de partida de trabajos fotográficos muy significativos de autores como César Justel o Cristina García Rodero. La democratización y la nueva organización del Estado también influyeron en el desarrollo de un turismo cultural que comenzó a generar imágenes de índole divulgativa simplificadoras de la complejidad de la fiesta y del rito. En lo que respecta a las imágenes del ámbito académico de la antropología surgieron algunas publicaciones que abundaron en la convivencia y complementariedad del texto y de la imagen y en otros aspectos novedosos, como las formas de representar acciones 
mediante la secuencia fotográfica procurada por cámaras dotadas de velocidades de obturación cada vez más rápidas.

\section{Referencias Bibliográficas}

BAROJA, J. C. (1989): "Presentación España Oculta”. En C. G. Rodero, España Oculta. Madrid: Lunwerg.

BRANDES, S. (2005): "Retratos en acción: la España de Cristina García Rodero”. En VV.AA, Maneras de mirar. Lecturas antropológicas de la fotografía. Madrid: Consejo Superior de Investigaciones Científicas, pp. 229-244.

BRISSET, D. E. (2009): “Investigar las fiestas”. En Gazeta de antropología, $\mathrm{n}^{0}{ }_{25}$ 1. Artículo 13. http://digibug.ugr.es/html/10481/6852/G25 13DemetrioE Brisset Martin.html.

CALVO, E. G. (1991): Estado de fiesta. Madrid: Espasa Calpe.

CARANDELL, L. (2001): “Los porqués de Fernando Herráez”. En Fernando Herráez. Madrid: La Fábrica.

CASTEllote, A. (1998): “Imágenes inquietantes”. En Koldo Chamorro. Madrid: La Fábrica.

CONESA, C. (2000): “El instante decisivo”. En Cristóbal Hara. Madrid: La Fábrica.

DE MiguEL, J. M. (1999): “Fotografía”. En M. J. Buxó, \& J. M. de Miguel, De la investigación audiovisual. Barcelona: Cuadernos A Biblioteca Universitaria.

GONZÁLEZ, E. F. (2002): El carnaval en España. Madrid: Actas. Cuadernos de Cultura y Civilización.

GONZÁLEZ, I. (1998): “Prólogo”. En C. Hara, Vanitas. Murcia: Mestizo y Photovisión. 
MORÉRE MOLINERO, N. (1999): “Turismo Cultural”. En F. Baylón Mariné, 50 años del Turismo Español. Un análisis histórico estructural. Madrid: ed. Centro de Estudios Ramón Areces.

MUÑOZ CARRIÓN, A. (2008): “El patrimonio cultural material y el inmaterial: buenas prácticas para su preservación”. En Mediaciones sociales, $\mathrm{n}^{\mathrm{o}} 3$. Madrid: Universidad Complutense, $\mathrm{pp}$. 495-534.http://www.ucm.es/info/mediars/MediacioneS3/Indice/ MunozCarrion/munozcarrion.html

OLIVARES, R. (2005): 100 fotógrafos españoles. Madrid: Exit publicaciones. 